\title{
A PSICOLOGIA FRENTE A EDUCAÇÃO E O TRABALHO DOCENTE
}

\author{
Diana Carvalho de Carvalho*
}

\begin{abstract}
RESUMO. A influência da Psicologia na construção do ideário pedagógico, no início do século XX, teve como cenário o ingresso de uma grande massa de crianças nas escolas nas sociedades industrializadas e o advento das idéias evolucionistas, que apontavam a necessidade imperiosa de estudo e compreensão do desenvolvimento infantil. Entre as temáticas que expressam as discussões educacionais que ocorreram em todo esse século e, até hoje, são questões presentes no debate da área, podemos destacar: a relação entre desenvolvimento e aprendizagem, a importância da educação para o desenvolvimento do psiquismo e o papel do professor no processo ensino-aprendizagem. O objetivo do presente artigo é examinar como aparecem tais temáticas no pensamento de J. Dewey, E. Claparède, J. Piaget, H. Wallon e L.S. Vygotsky. É possível identificar duas posições entre as quais se situam esses autores: a) aqueles que subordinam o processo pedagógico ao desenvolvimento das estruturas cognitivas da criança, considerando que o conteúdo básico a ser desenvolvido na educação é o próprio processo de pensamento; b) os que consideram que há um papel definido para a escola, o de ensinar conteúdos científicos e socialmente relevantes, ou seja, possibilitar à criança o domínio dos conhecimentos exigidos pela sociedade para o futuro, considerando que tal aprendizagem é um dos principais motores do desenvolvimento.
\end{abstract}

Palavras-chaves: Psicologia e Educação; teóricos da Psicologia; desenvolvimento e aprendizagem.

\section{PSYCHOLOGY, EDUCATION AND TEACHING}

\begin{abstract}
The influence of psychology on constructing the pedagogic principles at the beginning of the $20^{\text {th }}$ century had as its scenario a great number of children entering schools in the industrialized societies and the advent of evolutionist ideas which pointed out the absolute necessity to study and understand children's development. Among the themes which run through educational debates and occurred all along the century and, until today are present, we can highlight: the relation between development and learning, the importance of education in developing psychism, and the teacher role in the teaching/learning process. The purpose of the present article is to examine how these themes appear in the thoughts of J.Dewey, E. Claparède, J. Piaget, H. Wallon, and L.S. Vygotsky. It is possible to identify two differing groups in relation to these themes: (i) those who subordinate the pedagogical process to the development of the child's cognitive structure, considering that the basic content to be developed by education is the thinking process itself; (ii) those who consider that there is a definite role to be played by the school, that of teaching scientific and social relevant contents, that is to say, enable the child to control the knowledge demanded by society, considering that such learning process is one of the main vehicles of development.
\end{abstract}

Key words: Psychology and education; psychology theorists; development and learning.

$\mathrm{O}$ recurso à Psicologia tem sido uma marca constante no modo de encarar e buscar soluções para os problemas educacionais da modernidade. No Brasil, esta relação estreitou-se nas primeiras décadas do século XX, mais precisamente nos anos 20 e 30, momento em que a sociedade brasileira se via às voltas com as exigências da modernidade capitalista ${ }^{1}$. À Psicologia, com suas técnicas inovadoras, era atribuído o papel de disciplina coadjuvante na construção de um novo homem, especialmente por sua contribuição aos aspectos metodológicos do ensino, ou seja, o como ensinar. Naquele momento, esta questão revestia-se de importância fundamental diante da necessidade de escolarização das massas, já que eram altos os índices de analfabetismo no País e os discursos modernizadores de importantes educadores nacionais como, por exemplo, Lourenço Filho (1930), exigiam sua erradicação.

\footnotetext{
Professora doutora em História e Filosofia da Educação, Universidade Federal de Santa Catarina (UFSC).

Endereço para correspondência: Rua Pádova, 74 ap. 204, Bairro Córrego Grande, Florianópolis - SC. E-mail: dianacc@ terra.com.br

1 Sobre a história da Psicologia no Brasil, consultar Lourenço Filho (1994), Massimi (1990) e Pessotti (1988).
} 
O estudo do desenvolvimento infantil foi um dos eixos da discussão dos autores que se dedicaram à Psicologia e à Educação no início do século XX, que ficou conhecido como o "século da criança".

Segundo Warde (1997, p.303), a criança afigurase como o ponto "de virada" das relações entre Psicologia e Filosofia e, por decorrência, entre a Psicologia e a Pedagogia. Os fundamentos desta discussão estão enraizados nas teorizações realizadas no momento em que havia a preocupação com a constituição de uma pedagogia científica e com o futuro da própria ciência psicológica ${ }^{3}$.

As descobertas realizadas, na época, nos campos da Fisiologia, da Biologia e das ciências experimentais exerceram influência direta sobre a ciência psicológica, como demonstra Cunha (1994): as descobertas da Fisiologia evidenciaram a importância das atividades cerebrais para intermediar a interação entre o organismo e os estímulos ambientais; na Biologia as idéias evolucionistas realçaram o papel da adaptação do organismo ao meio no processo de evolução das espécies; e as influências das ciências experimentais sobre a teoria do conhecimento fizeram com que o conceito de inteligência, considerada como capacidade adaptativa e operante do organismo sobre o meio, ganhasse força e importância sobre o conceito de espírito.

Ao mesmo tempo, configuravam-se novas condições para o desempenho do trabalho nas sociedades industrializadas, especialmente a exigência de preparação formal, o que levou à dispensa do trabalho infantil e ao ingresso de uma grande massa de crianças nas escolas. Segundo Leite (1972), no momento em que as crianças chegaram às escolas surgiram três problemas que ainda hoje são objeto de

A expressão "século da criança" foi cunhada por Suchodolski (1978, p. 83), mas a importância do estudo da criança nas discussões pedagógicas é destacada por autores como Charlot (1983), na Europa, e Leite (1972), no Brasil.

3 A relação entre Filosofia e Psicologia é tema discutido por Warde (1990); a autora demonstra como o Positivismo opera a dissolução da concepção clássica de Filosofia, tornando outras ciências suas herdeiras. À Psicologia foram entregues os temas referentes à Teoria do Conhecimento e ao humano individualmente considerado; à Sociologia couberam os temas relativos ao coletivo; e à Epistemologia, considerada como Teoria da Ciência, aqueles que tratavam da normatização dos procedimentos de investigação científica. Foi justamente sobre o campo educacional que as ciências humanas, já positivizadas, exerceram suas maiores influências conformando, pragmática e empiricamente, as práticas $\mathrm{e}$ as instituições educacionais. A Psicologia assumiu como referência, para o estudo dos fatos humanos, as leis da natureza, postulando a prevalência do método e da objetividade. atenção de psicólogos e educadores: a inteligência, a aprendizagem e as diferenças individuais.

As idéias evolucionistas apontavam a necessidade imperiosa de estudo e compreensão do desenvolvimento infantil, pois a criança já não era considerada um adulto em miniatura, e o ingresso massivo das crianças na escola exigia a explicação dos diferentes resultados por elas alcançados no processo de escolarização. Essas foram questões de pesquisa a que se dedicaram psicólogos e educadores da época.

Entre as temáticas que expressam as discussões educacionais que ocorreram em todo o século XX, e até hoje são questões presentes no debate da área, podemos destacar: a relação entre desenvolvimento e aprendizagem, a importância da educação para o desenvolvimento do psiquismo e o papel do professor no processo de ensino-aprendizagem.

O objetivo do presente artigo é examinar como foram tratados esses temas no pensamento dos teóricos da Psicologia que tiveram grande influência sobre as idéias pedagógicas do século XX. Consideramos que tal análise pode auxiliar a elucidação de questões que se colocam ainda hoje nas discussões pedagógicas e sobre as quais o psicólogo é chamado, constantemente, a posicionar-se.

\section{J.F. HERBART E J. DEWEY: A IMPORTÂNCIA DO MÉTODO E DA REFLEXÃO PARA A EDUCAÇÃO}

$\mathrm{O}$ primeiro dos grandes pensadores que revelou preocupação com os fundamentos científicos que deveriam nortear a ação pedagógica foi o filósofo alemão Johann Friedrich Herbart (1776-1841). Herbart acreditava ser necessário, naquele momento, explicar cientificamente o processo de aquisição de conhecimento, já que as práticas pedagógicas não deveriam mais pautar-se pelo bom senso ou pela arte de ensinar. Seu pensamento pedagógico alicerçava-se em duas bases: na Ética, entendida como filosofia prática, que tinha como tarefa estabelecer os fins da educação; e na Psicologia, ciência que definiria os meios racionais para se chegar à educação.

Percebe-se em Herbart um grande esforço no sentido de explicar o funcionamento da vida mental. Suas idéias tiveram forte influência da teoria kantiana, o que o leva a propor a consciência como núcleo da vida mental, formada por representações do real e tendo como características a unidade e a operação sobre si mesma; concebia “(...) a psicologia como meio para a educação articular e organizar, na reflexão, a experiência empírica das representações diversas e conflitantes" (Costa,1993, p.135-136). 
Herbart foi um importante crítico da teoria das faculdades mentais para a explicação da vida psíquica, que era a base teórica da educação tradicional clássica, vigente na maioria dos sistemas escolares europeus e norte-americanos. A teoria das faculdades mentais postulava que a mente era dotada de faculdades inatas, como atenção, percepção e memória, que deveriam ser treinadas pelo exercício, pela repetição.

Ao serem divulgadas as idéias de Herbart fora da Alemanha, no final do século XIX, Warde (1997) destaca que foi John Dewey (1859-1952), educador estadunidense, um dos primeiros a admitir a importância da crítica herbartiana para o campo educacional.

Na avaliação de Dewey (1959), o grande mérito de Herbart foi postular que o ensino não é tarefa do acaso ou da rotina, e deve-se considerá-lo uma atividade consciente, intencional, com método e processo definidos. Nesta perspectiva, é atribuído um papel exclusivo à matéria de estudo, ao conteúdo, para o desenvolvimento mental e moral da criança; ou seja, "o espírito consiste naquilo que foi ensinado" (Dewey, 1959, p.77). O professor assume, nessa perspectiva, uma importância fundamental, pois tem o dever de instruir os discípulos, através de métodos consciente e adequadamente formulados e empregados.

A crítica de Dewey a Herbart recai sobre a omissão do aspecto ativo da aprendizagem da criança. Dewey discordava da forma exagerada de conceber a influência da matéria apresentada do exterior sobre a formação do espírito, já que considerava a criança “(...) um ser vivo de funções ativas e especiais que se desenvolvem pela redireção e combinação em que entram quando se põem em contacto ativo com o seu ambiente" (Dewey, 1959, p. 77).

Além disso, a educação não era simplesmente o resultado da instrução mas, sim, “... uma reconstrução ou reorganização da experiência, que esclarece e aumenta o sentido desta e também a nossa aptidão para dirigirmos o curso das experiências subseqüentes" (Dewey, 1959, p. 83).

Dewey concebe o homem em um processo de contínua interação com o meio que o circunda, percebe-o agindo sobre o meio ambiente e tendo de adaptar-se às condições oferecidas, ao mesmo tempo em que esta adaptação resulta em uma melhor utilização deste mesmo meio. O homem se constrói na ambiência social, pois "o meio social cria as atitudes mental e emocional do procedimento dos indivíduos" (Dewey,1959, p.17), exercendo um influxo formativo e educativo.

Assim, a escola teria como papel ser um meio especialmente preparado para influir na direção mental e moral dos que a freqüentam, cumprindo três funções especiais, conforme define Dewey (1959): a) proporcionar um ambiente simplificado, selecionando as experiências úteis e estabelecendo uma progressão, com o objetivo de conduzir os alunos à compreensão real das coisas mais complexas; b) eliminar os aspectos desvantajosos do meio ambiente que exercem influência sobre os hábitos mentais; c) coordenar, na vida mental de cada indivíduo, as diversas influências dos vários meios sociais em que vive.

Percebe-se que à escola é atribuído um papel fundamental de selecionar as experiências úteis realizadas pela humanidade para construir os conteúdos cognitivos necessários a uma sociedade futura mais perfeita, uma sociedade democrática; além de harmonizar o ambiente social para possibilitar o desenvolvimento do pensamento reflexivo, exigência dessa sociedade ${ }^{4}$. A ela não cabe ensinar a lógica de investigação, que é inerente à espécie, mas criar condições para o seu desenvolvimento.

Os pontos essenciais para o desenvolvimento do pensamento reflexivo pela escola podem ser assim sintetizados:

(...) primeiro, que o aluno esteja em uma verdadeira situação de experiência - que haja uma atividade contínua a interessá-lo por si mesma; segundo, que um verdadeiro problema se desenvolva nesta situação como um estímulo para o ato de pensar; terceiro, que ele possua os conhecimentos informativos necessários para agir nessa situação e faça as observações necessárias para o mesmo fim; quarto, que lhe ocorram sugestões para a solução e que fique a cargo dele desenvolvê-las de modo bem ordenado; quinto, que tenha oportunidades para pôr em prova suas idéias, aplicando-as, tornandolhes clara a significação e descobrindo por si próprio o valor delas. (Dewey, 1959, p.179180).

Apesar de enfatizar a atividade do aluno, Dewey não desconsidera o papel do professor no processo educativo, já que o pensamento depende de fontes informativas e de alguém que as organize adequadamente para o seu desenvolvimento, sem, no

4 Cunha (1994, p. 35) considera que, na concepção deweyana, o pensamento reflexivo tem uma função instrumental, ou seja, origina-se no confronto com situações problemáticas, sendo sua finalidade prover o homem de formas mais adequadas de comportamento para enfrentar as situações, o que gera consequiências tanto intelectuais quanto morais. 
entanto, fornecer soluções já prontas para os problemas.

Como Herbart, Dewey considera o ensino uma atividade consciente, intencional, com método e processo definidos. Diferentemente de Herbart, no entanto, Dewey não separa os fins dos meios da educação. Ao postular que o fim da educação seria a construção de uma sociedade democrática, acredita que, necessariamente, os meios deveriam estar relacionados a isto, sendo possibilitadores desta empreitada. O conflito entre indivíduo e sociedade, que se manifesta em objetivos distintos para a educação - desenvolvimento do pensamento ou adaptação às condições sociais -, não tem sentido para Dewey. Para ele, educar implica desenvolver o pensamento do indivíduo em contato com a cultura a que pertence.

Cabe destacar que Dewey é identificado como um dos mais importantes representantes do escolanovismo, que foi, segundo Lourenço Filho $(1978)^{5}$, um movimento que floresceu no início do século XX e tinha por base um conjunto de princípios que procuravam dar um novo tratamento aos problemas da educação em geral, ou seja, o trabalho escolar, suas condições e resultados, mediante novos pressupostos e métodos de investigação científicos.

\section{O PENSAMENTO DE E. CLAPARÈDE: O DESENVOLVIMENTO INFANTIL COMO FUNDAMENTO DA PEDAGOGIA CIENTÍFICA}

Apesar de também ser um dos representantes do movimento escolanovista e compartilhar a crítica feita pela Psicologia Funcionalista dos Estados Unidos à escola tradicional e à filosofia especulativa e metafísica, Edouard Claparède apresenta algumas diferenças, especialmente com relação a Dewey. Foi pela Filosofia que Dewey ingressou na Psicologia, abordando-a, a princípio, do ângulo da teoria do conhecimento (Claparède, 1954); ele mesmo, no entanto, teve um ingresso diferente na Psicologia, pela Biologia (Claparède, 1959). Esta diferença teve consequiências importantes para o desdobramento de sua obra, já que é do ponto de vista biológico e experimental que procura compreender a criança.

Claparède acreditava que somente a Psicologia poderia dar um fundamento científico à Pedagogia, sendo necessário estudar as manifestações naturais da

5 Foram consultadas duas edições do livro de Lourenço Filho Introdução ao estudo da Escola Nova, as de 1930 e de 1978; a segunda é uma edição revisada pelo autor e ampliada. criança e a elas conformar a ação educativa. Este estudo deveria ser feito através de pesquisas científicas relativas à criança e ao desenvolvimento mental, sendo fundamental a preparação dos futuros educadores, tanto no sentido de informá-los das novas descobertas psicológicas, como para desenvolver neles o espírito científico. Foi com este objetivo que Claparède criou, em 1912, o Instituto Jean-Jacques Rousseau, que pretendia ser uma escola das ciências da educação, aberta a todos os educadores, e um laboratório de pesquisas (Claparède, 1959).

$\mathrm{Na}$ sua opinião, Herbart não conseguiu realizar seu intento de fundamentar cientificamente a Pedagogia, por não possuir uma base psicológica suficiente, ou seja, não dava bastante importância ao domínio afetivo e às inclinações individuais, ignorava a hereditariedade e não conseguiu fundamentar cientificamente sua doutrina do interesse. Segundo o autor (Claparède, 1959), dois foram os principais defeitos da Psicologia herbartiana que impediam de torná-la a base verdadeira e necessária para a educação: a) sua Psicologia não era uma Psicologia da criança; b) não era uma Psicologia experimental sancionada pela experiência.

A preocupação de Claparède era alcançar uma visão de conjunto da vida mental e de seu mecanismo. Foi com base na concepção biológica que encontrou elementos para compreender o dinamismo da conduta, ancorando o fundamento do processo cerebral no acordo entre a necessidade do organismo e a reação adequada capaz de satisfazê-la, acordo este indispensável à manutenção da vida (Claparède, 1959). Tal concepção biológica levava-o a encarar os fenômenos psíquicos sob o ponto de vista do seu papel, de sua função na vida, de sua utilidade. A pergunta era: para que serve a inteligência?

É dessa perspectiva que compreende a inteligência como um instrumento de adaptação, que entra em jogo quando falham os outros instrumentos de adaptação biológica, que são o instinto e o hábito. Assim, a inteligência corresponde à necessidade de adaptação e, do ponto de vista biológico, está em pé de igualdade com todas as outras atividades que são estimuladas pela necessidade.

Claparède (1954, p.110) diferencia inteligência de pensamento, definindo-a como "a capacidade de resolver problemas novos por meio do pensamento". Pode-se dizer que o homem pensa porque é inteligente. As questões próprias do pensamento são veracidade e objetividade, pertinentes ao campo da teoria do conhecimento; considerava que à Psicologia cabia estudar a inteligência e, conseqüientemente, a aprendizagem. 
Atribuía ao psicólogo duas missões complementares: descobrir as leis do desenvolvimento que servem para todos os indivíduos, e ao mesmo tempo determinar as diferenças individuais que existem entre as crianças, classificando-as em diversos perfis mentais e psicológicos (Claparède, 1930). Justamente porque está apoiado na Biologia, entende que a individualidade nada mais é do que o resultado da variação proporcional dos caracteres da raça em seus diversos representantes (Claparède,1930). Assim, o problema da individualidade reduz-se a identificar as aptidões fundamentais que distinguem entre si os diferentes indivíduos e que podem servir para classificá-los em determinado número de tipos bem distintos.

Compreendendo aptidão como “... uma disposição natural para comportar-se de certa maneira, a compreender ou sentir de preferência certas coisas ou a executar certas espécies de trabalho" (Claparède, 1959, p.140), considera fundamental que a escola leve em conta as diferenças de aptidão e inteligência e propicie ao aluno o desenvolvimento de suas habilidades particulares, porque "ir contra o tipo individual é ir contra a natureza" (Claparède, 1959, p. 149). É neste contexto que se insere sua preocupação com os processos de diagnóstico psicológico através dos testes, um dos aspectos de sua obra que mais influência teve sobre o trabalho de Lourenço Filho, no Brasil.

Podemos identificar consequiências pedagógicas deste pensamento distintas das daquele proposto por Dewey. Uma das diferenças é a forma com que os autores compreendem a relação entre os fins e os meios da educação: para Dewey não deveria haver separação entre os fins e os meios da educação, ou seja, entre a Psicologia e a Filosofia; já Claparède advoga esta separação, enaltecendo o papel da Psicologia experimental para a ação pedagógica e afirmando que "(...)a maneira de ensinar é, até certo ponto, independente do fim último da educação" (Claparède, 1930, p.174). Ao estabelecer esta divisão, também subordina os conteúdos do ensino, o saber, ao desenvolvimento da inteligência; em outras palavras, a escola deve ensinar para desenvolver as características da inteligência (Claparède, 1954, p.38).

O papel do professor pode ser assim sintetizado:

(...) o educador, em vez de ser um plasmador de almas e espíritos, tornar-se-á um estimulador de interesses; em vez de ficar no meio do palco (onde muitas vezes pontifica, sem outros resultados tangíveis, a não ser a satisfação de suas tendências autoritárias), deverá, daí em diante, permanecer nos bastidores, de onde disporá e organizará o meio da maneira mais favorável ao despertar das necessidades intelectuais e sociais da criança e ao início de suas andanças intelectuais, de sua atividade, de seu esforço. Função menos decorativa do que a que lhe reserva a escola tradicional, mas também tão mais eficaz! E função bem mais difícil e delicada também! Logo, não é mais modesta, senão na aparência! (Claparède, 1959, p. 165-166).

As diferenças entre Dewey e Claparède também se manifestam na forma de encarar a relação entre Psicologia e Educação. Warde (1997) salienta que o primeiro considera que a Psicologia, entre outras ciências, pode contribuir para a organização do campo pedagógico; já o segundo considera que o pedagógico é, por excelência, um campo de aplicação dos conhecimentos psicológicos, isto é, um campo subordinado à ciência psicológica.

\section{O PENSAMENTO DE J. PIAGET: A EQUILIBRAÇÃO COMO FATOR CENTRAL DO DESENVOLVIMENTO}

É no contexto educacional dos anos 1930, no bojo do movimento escolanovista, que se defendia a importância de conhecer a criança, e foi através da influência poderosa de Claparède que as idéias de Jean Piaget (1896-1980) foram difundidas no Brasil. Piaget foi um dos mais importantes colaboradores de Claparède no Instituto J.-J. Rousseau, tendo ingressado na instituição em 1921, convidado pela originalidade de seus trabalhos e da metodologia de pesquisa utilizada. Sua preocupação principal, diferentemente de Claparède, não era com as questões educacionais mas, sim, com as questões epistemológicas. Realizou uma série de pesquisas visando a descrever e compreender diversos aspectos do desenvolvimento infantil, tendo como pano de fundo a questão central: como o ser humano constrói o conhecimento, ou seja, passa de um estado de menor conhecimento para outro de maior conhecimento. Mesmo não manifestando uma preocupação explícita com a educação, suas idéias muito agradaram aos educadores brasileiros (Vasconcelos, 1996).

$\mathrm{O}$ fato de ter participado de instituições internacionais como a UNESCO, durante vários anos ${ }^{6}$,

6 Conforme Vasconcelos (1996, p.53), Piaget dirigiu o Bureau International d'Education de 1929 a 1967 e participou da UNESCO (Organização das Nações Unidas para a Educação, a Ciência e a Cultura) de 1946 a 1980. 
tendo como pauta de discussão os problemas educacionais, fez com que Piaget se dedicasse, em alguns artigos, a estas questões. Sempre deixou claro, no entanto, que não era um pedagogo e que o trabalho de extrair aplicações pedagógicas das pesquisas que realizava deveria ser feito pelos educadores ${ }^{7}$.

Segundo Vasconcelos (1996), as publicações de Piaget dedicadas à educação têm em comum a defesa dos métodos ativos e a proposta de trabalho cooperativo como estratégia pedagógica para o desenvolvimento do pensamento experimental, da razão, da autonomia e dos sentimentos de solidariedade. A preocupação da educação deveria ser a de formar indivíduos capazes de produzir ou criar, e não apenas repetir.

Piaget (1978) postula que o desenvolvimento do ser humano está subordinado a dois grupos de fatores em constante interação: os fatores da hereditariedade e da adaptação biológica, dos quais depende a evolução do sistema nervoso e dos mecanismos psíquicos elementares, e os fatores de transmissão ou de interação sociais, entre os quais inclui a educação. Diferencia o aspecto psicossocial do desenvolvimento espontâneo ou psicológico, considerando que apenas este último é o desenvolvimento da inteligência mesma, ou seja, “(...) o que a criança aprende por si mesma, o que não lhe foi ensinado, mas o que ela deve descobrir sozinha" (Piaget, 1983, p.211).

$\mathrm{O}$ desenvolvimento da inteligência tem um ritmo temporal que envolve uma ordem e uma sucessão de estágios, pois “(...) a construção de uma nova noção suporá sempre substratos, subestruturas anteriores e isso por regressões indefinidas" (Piaget, 1983, p.215). Temos aí o fundamento da teoria dos estágios, que muito tem influenciado a educação brasileira ${ }^{8}$.

Piaget indica que esta determinada sucessão nos estágios do pensamento deveria ser respeitada nos procedimentos educacionais, pois “(...) a criança necessita passar por um certo número de fases caracterizadas por idéias que adiante considerará erradas, mas que parecem ser necessárias para o encaminhamento às soluções finais corretas" (Piaget, 1978, p.18). Assim, considera que “(...) só poderá haver vantagens em respeitar as etapas (com a

7 Piaget manifesta-se especificamente sobre esta questão no prefácio que escreve para o livro de Aebli (1974) denominado $A$ didática psicológica, que tinha como objetivo uma aplicação da sua teoria à didática.

8 Segundo Vasconcelos (1996, p.267), até os anos 1980, os piagetianos brasileiros estudavam, em sua maioria, os aspectos estruturais da explicação genética, ou seja, os estágios do desenvolvimento e sua caracterização em termos de estruturas operatórias. condição, é claro, de conhecê-las o bastante para avaliar sua utilidade)" (Piaget, 1978, p.18).

Tal posicionamento ratifica a ênfase que atribui à equilibração como fator principal do desenvolvimento, pois uma descoberta envolve sempre assimilação e acomodação das estruturas cognitivas, um jogo de regulações e compensações. A direção do desenvolvimento, portanto, é o da equilibração progressiva, o que implica a possibilidade de aceleração na construção destas estruturas, e ao mesmo tempo a impossibilidade de uma aceleração que ultrapasse certos limites. Os outros três fatores do desenvolvimento - hereditariedade (maturidade interna), experiência física (ação sobre os objetos) e transmissão social (o fator educativo) - são condições necessárias, mas não suficientes para o desenvolvimento (Piaget, 1983).

Se o desenvolvimento envolve estágios ordenados e sucessivos e depende, fundamentalmente, do processo de equilibração, a aprendizagem escolar fica subordinada às estruturas de pensamento já construídas pela criança. Assim, as questões educacionais, tais como o conteúdo, os métodos de ensino e o papel do professor, mesmo tendo um papel formador necessário ao próprio desenvolvimento, ficam subordinadas ao processo de construção das estruturas cognitivas, que têm como referência o sujeito universal, epistêmico. Piaget indica a importância do professor como uma figura que incite ao desafio e à reflexão, necessitando, para isso, conhecer os estágios do desenvolvimento cognitivo.

\section{O PENSAMENTO DE H. WALLON: A EDUCAÇÃO COMO FONTE DE CONHECIMENTO PARA A PSICOLOGIA}

Se a Psicologia proposta por Piaget foi a que se tornou hegemônica na escola brasileira, ela não era, no entanto, a única possibilidade de compreender-se a criança. No mesmo período da produção piagetiana havia um outro modo de conceber as contribuições psicológicas à educação, bem como as relações do indivíduo com o meio social e a cultura. Estas idéias estavam presentes na obra de Henri Wallon (18791962), médico francês que procurou explicar a evolução psicológica da criança e sempre manteve uma estreita relação com as questões educacionais em toda a sua trajetória profissional ${ }^{9}$.

\footnotetext{
Wallon participou da Sociedade Francesa de Pedagogia, presidindo-a de 1937 a 1962, e presidiu o Grupo Francês de Educação Nova de 1946 a 1962. Em 1944 foi nomeado pelo Ministério de Educação Nacional da França para
} 
Para esse autor, o estudo da criança foi marcado por uma interlocução constante com a educação: em 1925 fundou o Laboratório de Psicobiologia da Criança, destinado à pesquisa e ao atendimento clínico de crianças ditas "anormais", que funcionou durante 14 anos junto a uma escola na periferia de Paris. Esta escolha se pautou por um critério metodológico, pois acreditava que a criança devia ser estudada em todas as suas fases e em todas as suas manifestações, sendo o papel da investigação fazer perguntas ao real, levando em conta toda a sua complexidade (Wallon, 1975). Neste caso, a escola revelava-se um campo de estudo de particular importância.

Apesar de também ser crítico da educação tradicional, como a grande maioria dos pensadores de sua época, Wallon (1975) mostrava-se cético em relação a muitas das experiências do movimento da educação nova, particularmente às idéias de Montessori $^{10}$, pelo caráter individualista de suas propostas, que se revelava na forma de conceber a significação e a estrutura do coletivo escolar. Referese criticamente ao princípio que centra o processo educacional nas atividades espontâneas da criança:

\begin{abstract}
Numa época em que o domínio das ciências e das técnicas se torna cada vez mais a condição do progresso social, submeter a aquisição deste às invenções de que a criança é capaz parece uma distância desproporcionada entre as suas capacidades espontâneas e o imenso patrimônio social que lhe competirá fazer prosperar. Neste sistema de educação, o afastamento do professor que é o representante deste patrimônio prova de que modo o ponto de vista individual prevalece sobre o da sociedade (Wallon, 1975, p.232-233).
\end{abstract}

Para Wallon (1975), a escola é uma instituição socialmente determinada e anterior aos grupos de crianças que reúne, assim como esses grupos também são determinados por fatores sociais, tais como as condições demográficas, econômicas ou mesmo étnicas do bairro em que vivem. Por isso, uma perspectiva psicológica que aborde apenas o indivíduo

integrar uma comissão encarregada da reformulação do sistema de ensino francês, cujo relatório denominado "Plano Langevin-Wallon" foi apresentado em junho de 1947. Sobre o Plano Langevin-Wallon ver Merani (1977).

10 Montessori (1869-1953), médica e educadora italiana, foi uma das mais importantes representantes do movimento escolanovista em seu país. Sobre seu sistema educativo, ver Lourenço Filho (1978, p.179-186). não resolve os problemas inerentes à educação escolar.

O papel dos aspectos sociais na constituição do indivíduo é um dos pontos centrais de sua teoria e motivo de discordância das idéias de vários autores da época, especialmente das idéias de Jean Piaget. Wallon atribuía a Piaget o mérito de ter abordado diretamente a relação do indivíduo com o social, mas discordava de seu ponto de partida.

Wallon (1975) questionava a direção do desenvolvimento proposta por Piaget - do individual para o social, isto é, do egocentrismo para a descentração do pensamento e da objetividade; para ele, ao contrário, a individualização é uma aquisição, uma conquista a partir das impressões e reações que integram a criança, desde o início da vida, ao seu meio ambiente. Conforme sua concepção (Wallon, 1975), o processo de diferenciação do eu prossegue durante vários anos, e o indivíduo pertence ao seu meio social e físico antes de pertencer a si próprio.

Os meses iniciais de vida da criança caracterizamse por uma dependência absoluta daqueles que a cercam, o que indica, para Wallon (1975), que as primeiras relações utilitárias da criança não são suas relações com o meio físico, mas são relações humanas, relações de compreensão, que têm como instrumentos necessários meios de expressão e afetividade. É esta característica da espécie humana, os longos anos de dependência infantil, que torna o ser humano um ser geneticamente social.

Deste modo, o papel da hereditariedade, diferentemente do que propunha Claparède, fica relativizado na sua teoria, já que as atividades psíquicas são orientadas e hierarquizadas segundo os interesses preponderantes das sociedades. Também se diferencia de Piaget quanto à noção de fase desenvolvimento, discordando da linearidade, da ordenação normatizadora dos estágios de desenvolvimento propostos por aquele autor (Wallon, 1975). Wallon supõe um ritmo de desenvolvimento marcado por descontinuidade, rupturas, retrocessos e reviravoltas.

Wallon (1975) é taxativo ao afirmar: "Entre a psicologia e a educação, as relações não são de uma ciência normativa e de uma ciência ou de uma arte aplicadas". Propõe uma relação de simetria e complementaridade entre a Psicologia e a educação: já que a escola é um meio formador da personalidade total do indivíduo na nossa sociedade, o que acontece ali deve ser estudado na sua especificidade e pode, inclusive, auxiliar na constituição do conhecimento psicológico sobre a criança. 
Ao discutir a formação psicológica dos professores, Wallon (1975) explicita mais detalhadamente sua posição quanto a esta questão. Acredita que a formação dos professores deve ter uma ancoragem nas experiências pedagógicas que eles próprios podem realizar: Aponta a necessidade de prestar-se atenção a dois aspectos na experiência pedagógica: (1) as disposições que a criança apresenta, dependentes da idade e do seu temperamento individual e (2) as aptidões que exige e exerce cada disciplina. A direção que propõe, no entanto, é oposta àquela preconizada pelos reformadores escolanovistas, que tomaram como base para o ensino as atividades espontâneas da criança e o desenvolvimento do pensamento. Wallon acredita ser fundamental considerar as características específicas dos conteúdos de cada matéria e a natureza das tarefas escolares para, a partir delas, investigar quais os melhores meios para tornar estes conteúdos assimiláveis pelas crianças (Wallon, 1975). Os conteúdos escolares, neste caso, assumem um papel fundamental na dinâmica escolar e diante do processo de desenvolvimento intelectual da criança.

O papel do professor aqui é completamente diferente daquele proposto pelas outras teorias examinadas até então. Ele não se restringe ao acompanhamento das etapas de construção do raciocínio; ao contrário, ele interfere em todos os aspectos do processo de desenvolvimento, através da aprendizagem proporcionada à criança. $\mathrm{O}$ ponto de partida da investigação psicológica deve ser a ação dos professores, suas facilidades, dificuldades e necessidades no processo de ensinar. Há, na verdade, uma efetiva contribuição dos professores à elaboração teórica da Psicologia, já que conhecer a criança significa compreendê-la a partir do que acontece no espaço educacional. Nesta perspectiva teórica a ênfase da investigação sobre a criança é colocada no exame da realidade, e não em princípios teóricos abstratos que a expliquem desvinculada do seu meio ou que tratem dos conteúdos específicos de cada disciplina como capazes de, pela sua própria natureza, desenvolver habilidades mentais. O papel da investigação é fazer perguntas ao real, levando em conta toda a sua complexidade, sendo a elaboração de princípios teóricos decorrência da explicação desta realidade.

\section{O PENSAMENTO DE L. VYGOTSKY: A IMPORTÂNCIA DA ESCOLARIZAÇÃ̃O PARA O DESENVOLVIMENTO DO PSIQUISMO}

A importância do meio social para a constituição do indivíduo é uma idéia também radicalmente defendida por Lev S. Vygotsky (1896-1934), psicólogo russo, que teve o auge de sua produção nas década de 1920 e 1930. Este autor se inseriu nas discussões de sua época questionando as posições hegemônicas de que a compreensão das funções psicológicas superiores poderia ser derivada dos estudos da psicologia animal (princípios mecânicos de estímulo-resposta) ou que as propriedades do intelecto poderiam ser resultado da maturação biológica. Utilizando os princípios metodológicos do materialismo dialético, Vygotsky enfatizou as origens sociais da linguagem e do pensamento, procurando investigar os mecanismos através dos quais a cultura se torna parte da natureza de cada pessoa (Cole \& Scribner, 1991).

As implicações educacionais das suas reflexões teóricas sempre foram objeto de preocupação explícita de Vygotsky, traduzindo-se em textos que abordaram questões pontuais, tais como a relação entre aprendizado e desenvolvimento, o papel do brinquedo no desenvolvimento, a pré-história da linguagem escrita, o desenvolvimento dos conceitos científicos na infância. Em todos eles a especificidade da situação escolar está em pauta como um pressuposto norteador da investigação, qual seja, o de que o aprendizado escolar produz algo fundamentalmente novo no desenvolvimento da criança.

De acordo com Vygotsky, passar pelo sistema escolar faz com que o indivíduo classifique, conceitue e compreenda o mundo de modo diferente, porque aprende a lidar com conceitos teóricos que permitem formas de abstração e generalização mais complexas e independentes da experiência prática e direta da realidade. Tal afirmação está pautada por sua compreensão do papel da cultura no desenvolvimento do psiquismo: a cultura origina formas especiais de conduta, modifica a atividade das funções psíquicas, edifica novos níveis no sistema do comportamento humano em desenvolvimento (Vygotsky, 1995).

Na sua concepção os processos de aprendizado e desenvolvimento não são idênticos:

(...) a aprendizagem não é, em si mesma, desenvolvimento, mas uma correta organização da aprendizagem da criança conduz ao desenvolvimento mental, ativa todo um grupo de processos de desenvolvimento, e esta ativação não poderia produzir-se sem a aprendizagem. Por isso, a aprendizagem é um momento intrinsecamente necessário e universal para que se desenvolvam na criança essas características humanas não-naturais, mas formadas historicamente (Vygotsky, 1998, p. 115). 
Assim, a característica essencial da aprendizagem é que engendra a área de desenvolvimento potencial, ou seja, “(...) faz nascer, estimula e ativa na criança um grupo de processos internos de desenvolvimento no âmbito das inter-relações com outros, que, na continuação, são absorvidos pelo curso interior de desenvolvimento e se convertem em aquisições internas da criança" (Vygotsky, 1998, p.115).

Dessa forma, Vygostky indica a impossibilidade de se fixar um único nível de desenvolvimento e propõe o conceito de zona de desenvolvimento potencial para trabalhar com a capacidade potencial de aprendizagem da criança. Considera ser necessário determinar, pelo menos, dois níveis de desenvolvimento de uma criança: o nível de desenvolvimento efetivo e o âmbito de seu desenvolvimento potencial. $\mathrm{O}$ primeiro caracteriza-se como o nível de desenvolvimento das funções psicológicas que a criança conseguiu como resultado de um processo já realizado; o segundo pode ser definido como aquilo que a criança é capaz de fazer com o auxílio dos adultos ou por meio do processo de imitação ${ }^{11}$. Segundo o autor (Vygotsky, 1998), o que a criança é capaz de fazer no presente, com o auxílio dos adultos, pode fazer no futuro por si só.

Este conceito de zona de desenvolvimento potencial possibilitou uma nova perspectiva para o trabalho escolar: a ação escolar deve pautar-se não mais pelo passado, pela etapa já superada, mas pelo futuro, por aquilo que a criança poderá aprender com a intervenção dos processos culturais. A tarefa da escola, na opinião desse autor, consiste em fazer todos os esforços para encaminhar a criança nessa direção, para desenvolver o que lhe falta (Vygotsky, 1998). Este conceito traz implicações fundamentais também para a atuação do professor: ele é mais do que um animador ou um facilitador da aprendizagem, torna-se um dos elementos necessários e essenciais para o desenvolvimento humano.

Após o exame das idéias dos principais teóricos da Psicologia que influenciaram a educação no século

11 Vygotsky considera a imitação como uma das vias fundamentais para o desenvolvimento cultural da criança. Imitação não é simples formação de hábito, o processo de imitação pressupõe uma determinada compreensão do significado da ação do outro. A criança que não sabe compreender não saberá imitar o adulto que escreve (Vygotsky, 1995, p.137). Na análise que faz do uso dos signos e sua origem, Luria também chega a uma conclusão que permite perceber a importância do processo de imitação no desenvolvimento infantil: “(...) não é a compreensão que gera o ato, mas é muito mais o ato que produz a compreensão - na verdade, o ato geralmente precede a compreensão" (Luria, 1998, p. 188).
$\mathrm{XX}$, dispomos de elementos que podem auxiliar na compreensão da questão proposta inicialmente: como os autores da Psicologia posicionam-se sobre a educação e o trabalho do professor.

\section{ALGUMAS CONCLUSÕES}

Ao examinarmos o pensamento dos diferentes teóricos da Psicologia, encontramos duas posições distintas: a) uma que subordina o processo pedagógico ao desenvolvimento das estruturas cognitivas da criança, considerando que o conteúdo básico a ser desenvolvido na educação é o próprio processo de pensamento; b) outra que considera haver um papel definido para a escola, o de ensinar conteúdos científicos e socialmente relevantes, ou seja, possibilitar à criança o domínio dos conhecimentos exigidos pela sociedade para o futuro, considerando que tal aprendizagem é um dos principais motores do desenvolvimento.

No primeiro caso o papel do professor é observar, compreender e acompanhar a criança nas etapas de construção da inteligência, reorganizando didaticamente o material, de modo a torná-lo assimilável, de acordo com o estágio do desenvolvimento em que ela se encontra; aqui o que está em destaque é o indivíduo e o desenvolvimento das suas estruturas cognitivas.

A segunda posição defende um papel mais atuante do professor no processo de ensino-aprendizagem, porque considera que a aprendizagem estimula o desenvolvimento e não é apenas resultado deste; é salientado, nesse caso, o papel formador da educação escolar e sua relação com a cultura.

Constata-se a hegemonia da primeira posição no pensamento educacional brasileiro e, ao mesmo tempo, sua ineficácia para resolver os problemas educacionais presentes hoje na escola. Uma perspectiva que entenda a educação como um fenômeno histórico e cultural oferece, com certeza, melhores alternativas para que se possam encarar os desafios cotidianos da realidade escolar de nosso país.

Compreender as diferenças e semelhanças entre os autores; contextualizar a discussão científica presente no período em que viveram e perceber as interlocuções por eles realizadas, além de identificar as decorrências do pensamento de cada autor para a educação, são tarefas fundamentais para a compreensão do pensamento psicológico que foi se consolidando nos meios educacionais durante o século XX. 


\section{REFERÊNCIAS BIBLIOGRÁFICAS}

Aebli, H. (1974). Didática psicológica: aplicação à didática da teoria de Jean Piaget. Tradução: João Teodoro D’Olim Marote. ( $2^{\mathrm{a}}$ ed.) São Paulo: Nacional.

Charlot, B. (1983). A mistificação pedagógica: realidades sociais e processos ideológicos na teoria da educação. ( $2^{\mathrm{a}} \mathrm{ed}$.) Rio de Janeiro: Zahar.

Claparède, E. (1930). Psicología del niño y pedagogía experimental. Tradução: Domingo Barnés. Madrid: Francisco Beltran.

Claparède, E. (1954). A educação funcional. Tradução: J. B. Damasco Penna. (4 ${ }^{a}$ ed.) São Paulo: Nacional. (Trabalho originalmente publicado em 1931).

Claparède, E. (1959). A escola sob medida. Tradução: Maria Lúcia do Eirado Silva. Rio de Janeiro: Fundo de Cultura. (Trabalho originalmente publicado em 1951).

Cole, M. \& Scribner, S. (1991). Introdução. Em: Vygotsky, L. S. (1991). A formação social da mente. (pp. 1-16). São Paulo: Martins Fontes.

Coll, C. (1992). As contribuições da psicologia para a educação: teoria genética e aprendizagem escolar. Em: Leite, L. B. (Org.) (1992). Piaget e a escola de Genebra. (pp. 164-197). (2 ed.). São Paulo: Cortez.

Costa, M. L. A. (1993). Psicologia da educação: origens em Edward Lee Thorndike. Tese de Doutorado, Programa de Estudos Pós-Graduados em Educação: História e Filosofia da Educação, Pontifícia Universidade Católica de São Paulo.

Cunha, M. V. (1994). John Dewey: uma filosofia para educadores na sala de aula. Petrópolis: Vozes.

Cunha, M. V. (1995). A educação dos educadores: da escola nova à escola de hoje. Campinas: Mercado de letras.

Dewey, J. (1959). Democracia e educação. Tradução: Godofredo Rangel e Anísio Teixeira. ( $3^{a}$ ed.) São Paulo: Nacional. (Trabalho originalmente publicado em 1916).

Dewey, J. (1975). Vida e educação. Tradução: Anísio Teixeira. (9a ed.) São Paulo: Melhoramentos.

Leite, D. M. (1972). Psicologia da criança: história e principais campos de estudo. Em: LEITE, Dante M.. O desenvolvimento da criança: leituras básicas. (pp. 81-104). São Paulo: Companhia Editora Nacional.

Lourenço Filho, M. B. (1930). Introdução ao estudo da escola nova. (pp. 301-341). ( $2^{\mathrm{a}}$ ed.) São Paulo: Melhoramentos.

Lourenço Filho, M. B. (1978). Introdução ao estudo da escola nova: bases, sistemas e diretrizes da pedagogia contemporânea. (13 ed.) São Paulo: Melhoramentos.

Lourenço Filho, M. B. (1994). Ciências Psicológicas. Em: Azevedo, Fernando de. As ciências no Brasil. (1994). Vol II. (2a ed.) Rio de Janeiro: Editora da UFRJ.

Luria, A. R. (1998). O desenvolvimento da escrita na criança. Em: Vigotskii, L.S., Luria, A.R., Leontiev, A.N. (1998). Linguagem, desenvolvimento e aprendizagem. Trad: Maria da Penha Villalobos. (6 ${ }^{\mathrm{a}}$ ed.) São Paulo: Ícone. pp. 143-189. (Publicado originalmente em 1929).

Massimi, M. (1990). História da psicologia brasileira: da época colonial até 1934. São Paulo: EPU.

Merani, A. (1977). Psicologia e pedagogia: as idéias pedagógicas de Henri Wallon. Lisboa: Notícias.

Nagle, J. (1976). Educação e sociedade na primeira república. (2 $2^{\mathrm{a}}$ ed.) São Paulo: EPU; Rio de Janeiro: Fundação Nacional de Material Escolar.

Pessotti, I. (1988). Notas para uma história da psicologia brasileira. Em: Conselho Federal de Psicologia. Quem é o psicólogo brasileiro? (pp. 17-31). São Paulo: Edicon.

Piaget, J. (1978). Para onde vai a educação? Tradução: Ivete Braga. ( $6^{\mathrm{a}}$ ed.) Rio de Janeiro: José Olympio. (Trabalho originalmente publicado em 1971).

Piaget, J. (1983). Problemas de psicologia genética. Tradução: Célia E.A.Di Piero. (2aed.) São Paulo: Abril Cultural (Coleção Os Pensadores). (Trabalho originalmente publicado em 1972).

Suchodolski, B. (1978). A pedagogia e as grandes correntes filosóficas. ( $2^{\mathrm{a}} \mathrm{ed}$.) Lisboa: Horizonte.

Vasconcelos, M. S. (1996). A difusão das idéias de Piaget no Brasil. São Paulo: Casa do Psicólogo.

Vasconcelos, M. S. (1997). Raízes e caminhos do pensamento piagetiano no Brasil. Em: FREITAG, Bárbara (Org.). (1997) Piaget: 100 anos. (pp. 193-210). São Paulo: Cortez.

Wallon, H. (1975). Psicologia e educação da infância. Lisboa: Estampa.

Warde, M. J. (1990). A favor da educação, contra a positivização da filosofia. Em Aberto. Brasília, 45.

Warde, M. J. (1997). Para uma história disciplinar: psicologia, criança e pedagogia. Em: Freitas, Marcos C. (Org.). (1997). História social da infância no Brasil. (pp. 289-310). São Paulo: Cortez.

Vygotsky, L. S. (1995). Historia del desarrollo de las funciones psíquicas superiores. Em: VYGOTSKI, L.S. 1995. Obras Escogidas. (Vol. 3, pp. 11-340). Madrid: Visor.

Vygotsky, L. S. (1998). Aprendizagem e desenvolvimento intelctual na idade escolar. Em: Vigotskii, L.S., LURIA, A.R., Leontiev, A.N. (1998). Linguagem, desenvolvimento e aprendizagem. Trad: Maria da Penha Villalobos. (6 ${ }^{\mathrm{a}}$ ed.) (pp. 103-117). São Paulo: Ícone. (Trabalho originalmente publicado em 1933).

Recebido em 28/12/2001

Revisado em 14/04/2002 Aceito em 10/05/2002 